\title{
Soil carbon unearthed
}

\author{
Soils store vast quantities of carbon and have the potential to help mitigate or exacerbate climate change. We need \\ to better understand the interplay of chemical, physical and biological processes that govern soil carbon cycling \\ and stability.
}

$\mathrm{T}$ he world's soils contain more carbon than terrestrial vegetation and the atmosphere combined. Although most climate change studies focus on carbon in the skies above us, researchers are also increasingly looking to the ground below. Recognition of the crucial importance of this distinctly heterogeneous carbon reservoir has taken researchers from the tropics to the poles in search of answers. With this issue, we present a collection of articles from Nature Geoscience that highlight the dynamic vulnerability of soil carbon to anthropogenic environmental change.

Soil organic carbon is composed of soil microbes, decaying organic matter and degradation products like humus. The long-term stability of this huge carbon pool is dependent on the relative balance between inputs and outputs. Carbon inputs come from the growth of plants and their roots, the transfer of carbon-rich compounds from roots to soil microbes, and the decomposition of leaf litter. Outputs are governed by microbial respiration, which converts organic carbon back to carbon dioxide, soil erosion and leaching.

The global distribution and residence time of soil organic carbon is largely controlled by climatic factors, which influence photosynthesis, decomposition and respiration rates. For example, soils in high-latitude regions tend to be carbon-rich as the cold temperatures keep respiration rates down, while higher respiration rates in the warmer tropics result in less stored soil carbon. Climate warming and human disturbance of ecosystems are destabilizing the balance between inputs and outputs and causing soil organic carbon loss, which in turn exacerbates climate change.

There is striking evidence of the human influence on soil carbon stocks. As early as about 4,000 years ago, deforestation by the Maya caused reduced carbon retention in soils ${ }^{1}$. Modern deforestation continues to mobilize old, labile carbon and release it to rivers where it is respired and emitted as

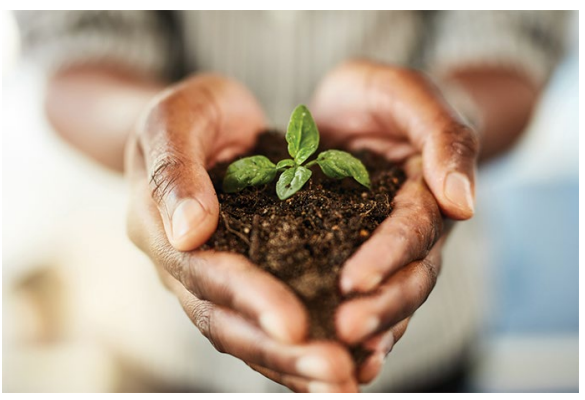

Credit: Peoplelmages

carbon dioxide ${ }^{2}$. Similarly, the drainage of tropical peatlands drives subsidence and soil carbon loss ${ }^{3}$, while soils in coastal ecosystem are under threat from anthropogenic perturbations such as sea-level rise and eutrophication ${ }^{4}$. Conservation of these vulnerable ecosystems is needed to minimize soil carbon losses.

Global warming and wildfires increasingly threaten permafrost regions in thawing what were perennially frozen, carbon-rich soils. An Article by Keuper et al. demonstrates how microbial processes and decomposition in permafrost soils lead to carbon loss, a feedback exacerbated by the increasing density of plants taking root as soils thaw. Adding to the concern, an Article by Shi et al. reveals that permafrost soils contain the oldest soil organic carbon pool on Earth. This implies that the accumulation and sequestration of carbon in these soils is much slower than predicted by models (see News \& Views by Billings and de Souza), while also highlighting the vulnerability of these ecosystems and their carbon stocks to the abrupt changes brought on by climate change.

Microbes - capable of both respiring organic carbon and producing stable recalcitrant pools - have a complex relationship with soil carbon. Microbes form a large component of soil organic carbon through their biomass and the organic matter transformations they mediate. Plant-microbe interactions can also influence soil carbon persistence ${ }^{5}$ : microbial formation of soil organic carbon below ground produces mineral-stabilized soil carbon more efficiently than leaf litter inputs above ground ${ }^{6}$. This dynamic interplay of soil-microbe, carbon-mineral and climatic feedbacks complicates attempts to determine simple relationships between warming and microbial respiration of soil carbon.

Researchers are increasingly thinking about how soil systems can be successfully managed to store more carbon and mitigate climate change. In a Perspective, Lehmann et al. describe how the long-term stability of soil carbon is a matter of having the right microbes in the right place at the right time, as not all microbes are capable of decomposing all molecules. They suggest that effective soil management to promote ecosystem health and soil carbon storage needs to be informed by these microscale interactions. Over the longer term the make-up of microbial communities is controlled by weathering processes, which set the nutrient availability in soils ${ }^{7}$, but how microbial communities respond over shorter timescales remains an open question.

As our understanding of soil systems advances, the importance of the carbon underneath our feet to our climate has become increasingly apparent. Leveraging carbon stored in soils could be a powerful climate mitigation strategy, the success of which depends on the careful conservation of vulnerable environments and well-informed process-based management.

Published online: 31 July 2020

https://doi.org/10.1038/s41561-020-0624-Z

References

1. Douglas, P. M. J. et al. Nat. Geosci. 11, 645-649 (2018).

2. Drake, T. W. et al. Nat. Geosci. 12, 541-546 (2019).

3. Hoyt, A. M., Chaussard, E., Seppalainen, S. S. \& Harvey, C. F. Nat. Geosci. 13, 435-440 (2020).

4. Spivak, A. C., Sanderman, J., Bowen, J. L., Canuel, E. A. \& Hopkinson, C. S. Nat. Geosci. 12, 685-692 (2019).

5. Cotrufo, M. F., Ranalli, M. G., Haddix, M. L., Six, J. \& Lugato, E. Nat. Geosci. 12, 989-994 (2019).

6. Sokol, N. W. \& Bradford, M. A. Nat. Geosci. 12, 46-53 (2019).

7. Doetterl, S. et al. Nat. Geosci. 11, 589-593 (2018). 